\title{
Plan ahead by embracing retrospective approach: global health
}

\author{
Arpita Saxena* \\ Department of Public Health Dentistry, Consultant Dental Surgeon, Jaipur, Rajasthan, India
}

Received: 05 July 2020

Revised: 09 August 2020

Accepted: 14 August 2020

\section{*Correspondence:}

Dr. Arpita Saxena,

E-mail: drarpitasaxena.18@gmail.com

Copyright: (c) the author(s), publisher and licensee Medip Academy. This is an open-access article distributed under the terms of the Creative Commons Attribution Non-Commercial License, which permits unrestricted non-commercial use, distribution, and reproduction in any medium, provided the original work is properly cited.

\begin{abstract}
Many countries worldwide are experiencing a see-saw pattern in health sector as individuals demand for health services rise exponentially during their fear and anxiety of disease and death. But medical care alone cannot bring health (physical/mental) to people living in rural/urban areas. It is the blending of natural and man-made variables to overcome poverty, unemployment, poor sanitation, and, not to be excused, ailing health. It is likely to expect significant health improvements in those respective areas if given a radical approach. To address the needs of public, World Health Organization came up with some strategies to improve health guidelines, reduce health risks, to have immense progress and to support a sound lifestyle to every human in 1970s that were to be fulfilled by 2000 . The term 'Health for All' was defined in 1981 in which its goals were interlinked with each other in some or the other way. For instance, to reduce crude death rate, some eradication programmes were being improvised and at the same time those programmes helped to increase life expectancy of individuals by improving quality of life. To put it in a nutshell, public health has always been a key factor of all time since the beginning of the universe, we need to realize that to diminish health inequalities, we have to amalgamate ancient and advanced technology in an effective pattern to improve health and address health issues as they begin to develop.
\end{abstract}

Keywords: Healthcare, Programmes, WHO

\section{INTRODUCTION}

Many countries worldwide are experiencing a see-saw pattern in health sector as individuals demand for health services rise exponentially during their fear and anxiety of disease and death. But medical care alone cannot bring health (physical/mental) to people living in rural/urban areas. It is the blending of natural and man-made variables to overcome poverty, unemployment, poor sanitation, and, not to be excused, ailing health. It is likely to expect significant health improvements in those respective areas if given a radical approach.

To address the needs of public, World Health Organization came up with some strategies to improve health guidelines, reduce health risks, to have immense progress and to support a sound lifestyle to every human in 1970s. As a result of some positive input, few demographic achievements were duly noted and described with their flaws for the reality check to have a better understanding in improving well-being for all.

\section{HEALTH FOR ALL 2000}

'Health for All' infers that it should be conveyed to individuals to achieve a satisfactory level of health in all the aspects like socially, financially, and environmentally.

The term has been popularized since the 1970s by Halfdan Mahler, former Director General of the WHO. Halfdan Mahler, defined Health for All in 1981 as:

'Health for All' means that health is to be brought within reach of everyone in a given country. And by 'health' is 
meant a personal state of well-being, not just the availability of health services- a state of health that enables a person to lead a socially and economically productive life. 'Health for All' implies the removal of the obstacles to health- that is to say, the elimination of malnutrition, ignorance, contaminated drinking water and unhygienic housing- quite as much as it does the solution of purely medical problems such as a lack of doctors, hospital beds, drugs and vaccines. ${ }^{1}$

Goals of 'Health for All' to be achieved by 2000 were as follows: 1) reduction of infant mortality from the level of 125 (1978) to below 60;2) to raise the expectation of life at birth from the level of 52 years to $64 ; 3$ ) to reduce the crude death rate from the level of 14 per 1000 population to 9 per $1000 ; 4)$ to reduce the crude birth rate from the level of 33 per 1000 population to $21 ; 5)$ to achieve a net reproduction rate of one; and 6) to provide potable water to the entire rural population.

The principle reason of 'Health for All' was to eradicate poverty, illness, general mortality rates in all cases- newborn and maternal and provide a clean environment socially, economically, and naturally.

Total 194 nations come under World Health Organization and these nations are divided into six regions where WHO headquarters are situated.

Table 1: WHO headquarters worldwide.

\begin{tabular}{|lll|}
\hline Regions & $\begin{array}{l}\text { No. of } \\
\text { countries }\end{array}$ & Headquarter \\
\hline African region & 47 & Congo \\
\hline Region of America & 35 & USA \\
\hline South-east Asia region & 11 & India \\
\hline European region & 53 & Denmark \\
\hline $\begin{array}{l}\text { Eastern Mediterranean } \\
\text { region }\end{array}$ & 21 & Egypt \\
\hline Western Pacific region & 27 & Philippines \\
\hline
\end{tabular}

Discussing every region of WHO, each goal of 'Health for All', was not truly satisfied, but full efforts were applied which can be effectively witnessed by numbers.

Between 1990 and 2008, the death rate for children under five was decreased by 28 per cent, from 100 to 72 deaths per 1,000 live births. Which means that, worldwide, less than 10,000 under-fives die each day. Many countries have shown better progress in handling child mortality. Almost one third of the 49 least developed countries have progressed to reduce mortality rates by 40 per cent or more over the past twenty years. However, while we were making progress, factually speaking, the rate of progress was still short of the Millennium Development Goals (MDG) target of a two-thirds reduction by 2015 . $^{2}$

Since 1990, child mortality rates have been more than halved in Northern Africa, Eastern Asia, Western Asia,
Latin America, and the Caribbean. By contrast, many countries with unacceptably high rates of child mortality, most notably in sub-Saharan Africa, have made little or no progress in recent years. Sub-Saharan Africa has one fifth of the world's children under the age of five, and it accounted for half of their deaths (8.8 million) in 2008. In Southern Asia too, child mortality rates remain high. ${ }^{2}$

Egypt outperformed the MDG focus for reducing child mortality in children under-five. This accomplishment was supported by a huge extension in Measles Immunization Plan, which remained at 92\% in 2008. Vietnam's Expanded Program of Immunization profited more than $90 \%$ of children and pregnant ladies. In addition, in 2006, Bangladesh directed the world's biggest ever measles plan, immunizing 33.5 million kids between the ages of nine months and 10 years, over a 20day time span.

The Declaration of Alma Ata vowed to achieve "Health for All by 2000" by universal provision of primary health care in 1978.

The idea of primary health care amid 1970s gave a profoundly better approach for planning medicinal services strategically especially in developing nations like Africa, Asia, and Latin America. A noteworthy worldwide meeting on essential medicinal services composed in 1978 by the WHO and UNICEF in AlmaAta asked all nations and health-related agencies to ensure and advance the strength of the considerable number of individuals of the world.

As per the Alma-Ata statement, essential human services were made logically stable and socially satisfactory and innovative enough to all individuals and at a cost that the nation can afford and be a part of the development optimistically.

In India, the Government of India attempted to accomplish the objective by presenting new health programmes and by extending some on-going health programmes of 'Five-Year Plans'.

'Five Year Plans' started back in year 1951 to re-build a superior India. In this health report, health programmes of few five-year plans that lie within the time-period of 'Health For all' were properly noted. These programmes were distributed among 6 goals (as mentioned above) to achieve organized results. ${ }^{3}$

\section{Goal 1: Reduction of infant mortality rate (IMR) from the level of 125 (1978) to below 60}

IMR is universally regarded not only as the most important indicator of the health status of a community but also of the level of living of people in general. ${ }^{4}$

The main reason behind the infant mortality rate is ecological and social boundaries that counteract access to 
essential health assets and in this manner, add to an accelerated new-born death rate. The absence of immunization resulted due to narrow minded social activities like female feticide, and various other environmental variables that came into high new-born death rate all around.

In India, the rate assessed was 119.17 for each 1000 live births in $1978 .{ }^{5}$ As per 'Health for All' system by the WHO, first objective was to diminish the number of infant death rate to underneath 60 by the year 2000. In any case, looking at the information, in India, this objective was not fully satisfied but the rate drastically decreased when compared with 1978. In 2000, Infant mortality rate was 66 per 1000 live births. ${ }^{5}$ Programmes that were included to attain the goal were:

\section{Expanded programme on immunization}

The Government of India launched EPI in 1978 with the objective of reducing the mortality and morbidity resulting from vaccine-preventable diseases of childhood.

Immunization is the capable and financially stable weapon against vaccine preventable diseases. This programme was launched against six, most common diseases- diphtheria, pertussis, tetanus, polio, tuberculosis, and measles. It has two vital componentsvaccination of pregnant ladies and kids in the initial year of their life against those six diseases. In which, TT immunization of pregnant introduced in 1983 and Measles immunization in 1985. By November 1985, it was taken up by 30 regions and 50 medical colleges.

The Universal Immunization Programme (UIP) and oral rehydration therapy (ORT) were both propelled in 1985 and the Safe Motherhood Programme started amid the Eighth Plan was among the noticeable parts of the Family Welfare Programme. In the early 1990s, these projects were incorporated and additionally fortified to shape the Child Survival and Safe Motherhood (CSSM) Programme. In 1994, the CSSM Programme was further expanded to the Reproductive and Child Health services. These programmes had the coveted impact of diminishing infant mortality.

The main aim was to achieve 100 percent coverage of pregnant women with 2 doses of tetanus toxoid (or a booster dose), and at least 85 percent coverage of infant with 3 doses each of DPT, OPV, one dose of BCG and one dose of measles vaccine by $1990 .^{6}$

\section{Human milk banking programme}

In India, it started in 1989 at Lokmanya Tilak General Hospital in Mumbai. Asia's largest human milk bank which gets donation from 40 mothers every day and benefitting 3,000 babies every year. To reduce infant mortality rate, it was a great approach as breast milk is crucial for a new-born baby. It has sufficient nutritional and immunological properties to be considered as a pillar of a child health.

\section{Reproductive and Child Health Programme ( $\mathrm{RCH})$}

Child Survival and Safe Motherhood programme was expanded to Reproductive and Child Health Programme in 1990 s. RCH phase 1 started formally on $15^{\text {th }}$ October 1997. The main aim of this programme was to bring down the infant mortality rate by 60 per 1000 live births and maternal mortality rate $<400$ per 1 lakh.The programme also helped to achieve one another goal of 'Health for All', to bring down birth rate below 21 per 1000 population.

\section{Goal 2: To raise the expectation of life at birth from the level of 52 years to 64}

Life expectancy generally demonstrates the status of mortality rate which further defines the health status of the individuals. The shorter life expectancy is generally seen among poor people. Rural areas are more inclined to shorter life expectancy because of deficient access to health services.

Demographic data shows the average life expectancy in 1978 was 52.85 which expanded superbly to 62.63 by 2000. To raise an expectation of life, some health boost programmes are duly noted in this report. Programmes were:

\section{Iodine deficiency disorders programme}

India started Goiter Control Programme in 1962. The programme initiated nation-wide (instead of areaspecific) use of iodized salt. ${ }^{6}$

In 1992, the Central Council of Health, took a policy decision to iodize the entire edible salt in the country by the year 1992. In August 1992, the NGCP was renamed as National Iodine Deficiency Disorders Control Programme (NIDDCP) taking into its ambit control of the wide spectrum of IDD like mental and physical handicap and reproductive wastage. The Goal of the NIDDCP was to reduce the prevalence of IDD below $10 \%$ in endemic districts of the country. ${ }^{7}$

\section{National programme for control of blindness}

The National Programme for Control of Blindness (1976) was the continuation of Trachoma Control Programme which started back in year 1968. The first survey was done by ICMR in 1974 and quoted prevalence of blindness up to $1.38 \%$. In the second survey by WHO in 1986-89, the prevalence increased to 1.49 percent.

South East Asia Region of the WHO has close to 15 million of the world's 45 million blinds, a disproportionately high burden of one third of world's blindness for one quarter of the globe's population. ${ }^{8}$ South 
East Asia region also has half of the world's 1.5 million blind children. In all countries of the region, prevalence of Blindness has been observed to be higher among women, the elderly, and the rural population.

India was the first country to launch the national level blind control programme in 1976 as $100 \%$ centrally sponsored programme. In 1994-95, the programme decentralized with formation of district blindness control society.

Mid-term evaluation of World Bank project in 1997-98 indicated marginal (10-15\%) fall in prevalence. After that, mega eye camps in underserved areas launched in the 50th year of India's Independence in 1997-98. ${ }^{9}$

\section{National Mental Health Programme}

The Central Government launched the District Mental Health Program as a $100 \%$ centrally sponsored scheme during the 9th plan- 1996-97 at national level as a pilot project in one district each in Andhra Pradesh, Assam, Rajasthan, and Tamil Nadu.

The programme was extended to 7 more states during 1997-98- the states of Arunachal Pradesh, Haryana, Himachal Pradesh, Punjab, Madhya Pradesh, Maharashtra, and Uttar Pradesh. The programme was subsequently expanded to one district each in the States of Kerala, West Bengal, Gujarat and Goa and the union territory of Daman and Diu during 1998-99, Mizoram, Manipur, Delhi, and union territory of Chandigarh during 1999-2000.

\section{Goal 3: To reduce the crude death rate from the level of 14 per 1000 population to 9 per 1000}

Crude death rate in India has given positive results since quite a while from $19^{\text {th }}$ to $21^{\text {st }}$ century. The number was 14 per 1000 in 1978 which came down to 9 per 1000 in 2000 as per the strategy of the WHO. ${ }^{6}$

Broad objectives of Five-year plans (which was readily adopted in 1951) were: 1) to control or eradicate major communicable diseases; 2) strengthening of the basic health services through the establishment of primary health centres and subcentres; 3) population control, and 4) development of health manpower resources. ${ }^{10}$ Programmes included were:

\section{National Malaria Eradication Programme}

National Malaria Eradication Programme was launched in 1953, it was based on indoor residual spraying of DDT twice every year in endemic areas where spleen rates were over 10 percent. $^{6}$ The annual cases of malaria in India increased from 50,000 in 1961 to a peak of 6.4 million cases in $1976 .^{6}$ To defeat this issue, Modified Plan of Operation was presented in 1977. This led into significant decrease in the rate of malaria which was kept up to 1986. An expert committee was appointed by the Govt. of India during December 1994. The committee highlighted the epidemiological parameters to identify the high-risk areas and suggested specific measures to be undertaken for the effective control of malaria. The programme is implemented as per the guidelines of Malaria Action Programme from 1995. ${ }^{11}$

It was also causing economic burden. If the estimates of the Malaria Research Centre, Delhi were considered for calculation of economic loss, the cost would have been Rupees 68,600 million (US\$1,508 million) versus expenditures of Rupees 3,467.9 million (US\$76.2 million) for control. Thus, the net savings due to malaria control was estimated at Rupees 65,132.1 million (US\$1,431 million). These authors inferred that every Rupee invested in malaria control has produced a direct return of Rupees 19.70. The estimated man-days saved were $1,328.75$ million per year. ${ }^{12}$

Then back in 1997, World Bank assisted Enhanced Malaria Control Project in tribal districts of the state in which financial support was given on insecticide, staff training extending their knowledge on malaria, and health education to individuals. In 1999, programme was renamed to National Anti-Malaria Programme.

\section{National Filaria Control Programme}

During the Eighth Five Year Plan, it was envisaged to distribute anti-filarial drugs through primary health care delivery system in the rural areas of endemic states. It was introduced in 13 endemic districts in 7 states- Andhra Pradesh, Bihar, Kerala, Orissa, Tamil Nadu, Uttar Pradesh, and West Bengal. Initially, it was introduced in Tamil Nadu in 1966 and in other states, it made active in 1997.

Annual Mass Drug Administration with single dose of DEC was taken up as a pilot project covering 41 million population in 1996-97 and extended to 74 million population. This strategy was to be continued for 5 years or more to the population excluding children below two years, pregnant women, and seriously ill persons in affected areas to interrupt transmission of disease. ${ }^{13}$

\section{National Leprosy Eradication Programme}

The programme has been in operation since 1955. It gained momentum during the fourth five-year plan after it was made centralised in order to achieve early detection cases and Dapsone (DDS) monotherapy. In 1980, Government of India resolved to eradicate leprosy by 2000 as per 'Health for All' and constituted a working group. 6

\section{National Tuberculosis Programme}

The genius mind of Dr. Wallace Fox played a great role in this. He, through British Medical Research Council 
units in East Africa, India, Hong-Kong, and Singapore, handed over the greatest gift to the world- short course chemotherapy. With the introduction of Rifampicin and Pyrazinamide in the developed countries in early 1960s, a new era started in the battle against TB. This finding enabled to cut down the duration of treatment to 6-8 months. ${ }^{14}$

In 1983, Tuberculosis Research Centre, Madras (India), pilot tested SCC in 18 districts of the country to assess the feasibility of its implementation on a larger scale. Government of India (GOI) agreed to the policy of implementation of SCC in 1986 and scaled up the coverage to cover 252 districts with the regimens. ${ }^{15}$

In 1993, Government of India decided to take help from international agencies and Revised National TB Control Programme (RNTCP) was setup and adopted the internationally recommended strategy, Directly Observed-Treatment Short-Course (DOTS). The RNTCP took its roots in India in 1993 by pilot testing the carefully orchestrated management strategy in a limited area as Phase I project covering a population of about 18 million. From 1998-2001, the population coverage and expansion were scaled up to cover a population of about 350 million. ${ }^{16}$

\section{National Cancer Control Programme}

National Cancer Control Programme was started in 197576. But, due to inadequate cancer treatment facilities, programme was revised in 1984-85. Under this plan, budgetary help was given to registered voluntary organisations up to 5 lakhs by the state government for undertaking health education and early detection exercises in malignancy. A linkage with the regional cancer centre was made necessary to NGOs.

New initiatives were taken in 1998-99, when WHO made an appearance as a helping friend and funded to this programme. Sixteen training programmes were held throughout India and the PEP smear kits and can scan software were supplied to 12 Regional Cancer Centers. ${ }^{17}$

\section{National Guinea- Worm Eradication Programme}

The global campaign to eradicate guinea worm began in 1980 at the US Centres for Disease Control and Prevention (CDC). Guinea worm disease (GWD) eradication was targeted as an ideal indicator of success for the United Nations in 1981-1990.

International Drinking Water Supply and Sanitation Decade (IDWSSD) was confirmed because the disease could only be transmitted through contaminated drinking water. A year later, GWD eradication was adopted as a sub-goal of the IDWSSD. In 1984, CDC was designated as the WHO Collaborating Centre for Research, Training, and Eradication of Dracunculiasis. ${ }^{18}$
In February 2000, the International Commission for the Certification of Dracunculiasis Eradication recommended that India be certified free of Dracunculiasis transmission. ${ }^{6}$

\section{National AIDS Control Programme}

In 1987, National AIDS Control Programme started awareness of AIDS. Screening of blood for HIV, and testing of individuals with risk behaviour. By the end of this year, out of 52,907 who had been tested positive, 135 had HIV and 14 had AIDS and the reason was due to heterosexual sex only but by the end of 1980 , cause of an infection changed into drug injections mainly in Mizoram, Manipur, and Nagaland. ${ }^{19,20}$

By 1990s, Median Term Plan launched for four states and the four metros but when the prevalence of AIDS continues to rise unstoppably, in 1992 the Government of India set up the National AIDS Control Organization.

NACP phase 1 started during the eight-five-year plan from 1992-1997. Since AIDS do not have treatment, the only way to curb down its prevalence is to spread awareness towards the awareness of AIDS which is normally the last stage of HIV virus. Financial budget from the World Bank was US \$84 million and another US $\$ 1.5$ million in the form of technical assistance from the Word Trade Organization. ${ }^{21}$

NACP phase 2 started during the ninth five-year plan from 1997-2006. This was a 100\% decentralized phase including 32 states, and 3 municipal CorporationAhmedabad, Chennai, ad Mumbai through AIDS Control Societies. This phase mainly focused on decentralization of service delivery to create more awareness among the individuals. $^{22}$

\section{Japanese Encephalitis Control}

In India, the disease was first reported in the mid 1950's from Vellore in Tamil Nadu State, where cases of an encephalitis like illness were seen and serologically proven to be due to JE or closely related to it. Over the next decade, 52 cases of encephalitis presenting at the Christian Medical College, Vellore were identified to be JE. Around the same time, extensive serological surveys in South India revealed widespread flavivrus activity. ${ }^{23}$

Up until now, pandemics are happening in alternate years. Though for the prevention and control of Japanese Encephalitis, no separate funds are allocated. The strategies include proper case management, strengthening of the tertiary health care, and early diagnosis.

\section{Kala-Azar Control Programme}

Till 1990, the budgetary arrangement of Kala-Azar Control Program was a part of National Malaria 
Eradication Program then in 1991, it turned out as a centrally supported program.

\section{Dengue Fever Control}

Around sixty flare-ups were accounted amid the period 1956 to 1996 in Delhi. Since dengue diseases have the capability of quick spread leading to an acute health problem, 'Rule of Preparation of Contingency Plan' in case of an occurrence of epidemic of Dengue/Dengue haemorrhagic fever was prepared and sent to every one of the states.

\section{Goal 4: To reduce the crude birth rate from the level of 33 per 1000 population to 21}

India is considered the second most populous country. According to 'Health for All', crude birth rate ought to be 21 by 2000 yet it stays $24 \times 7$.

\section{National Family Welfare Programme- Since 1952.}

India propelled the National Family Welfare Program in 1951 with the goal of reducing the birth rate to the degree important to balance out the populace at a level steady with the necessity of the National economy. The Family Welfare Program in India is perceived as a need zone and is being actualized as a 100\% Centrally supported program.

During the $4^{\text {th }}$ plan, the aim was to reduce birth rate from 35 per thousand to 32 per thousand by the end of plan. 16.5 million couples, constituting about $16.5 \%$ of the couples in the reproductive age group, were protected against conception by the end of $5^{\text {th }}$ plan. ${ }^{16}$

The objective of the $5^{\text {th }}$ plan (1974-79) was to bring down the birth rate to 30 per thousand by the end of $1978-79$ by increasing integration of family planning services with those of Health, Maternal and Child Health (MCH) and Nutrition, so that the programme became more readily acceptable. $^{24}$

\section{Goal 5: To achieve a net reproduction rate of one}

Poverty and lack of education has dependably been characterized as India's most pessimistic attitude for increased population.

\section{National Population Policy}

In April 1976, Dr. Karan Singh, former Minister of Health, and Family Planning, announced the National Population Policy of India. This became a landmark in population policy. ${ }^{25}$
In 1983, the National Health Policy emphasized, securing the small family norm, through voluntary efforts and moving towards the zenith of achievement.

The policy hoped to reduce the nation's hardships, established how incentives would be allocated to those who participate in population management efforts, and sought to reduce the nation's birth rate from 35 to 25 per 1000 by $1984 .^{26}$

\section{Goal 6: To provide potable water to the entire rural} population

A national water supply and sanitation program was presented in the social part in the nation in 1954. The Government of India helped the States to set up special cleaning project to provide cleaned environment for the betterment of people.

\section{National Water Supply and Sanitation Programme}

The Government of India introduced the Accelerated Rural Water Supply Programme (ARWSP) in 1972-73 to assist States and Union Territories with $100 \%$ grants-inaid to implement drinking water supply schemes in villages.

In 1999-2000, Sector Reform Project was begun to include the community in usage, and administration of drinking water plans was promoted in 2002 as the Swajaldhara Program.

\section{ACCOMPLISHMENTS IN INDIA}

Accomplishments in India are presented in Tables below:

Table 2: Achievements of few Five-Year plans. ${ }^{3}$

\begin{tabular}{|lll|}
\hline (In numbers) & $\begin{array}{l}\text { Sixth plan } \\
(\mathbf{1 9 8 0 - 8 5})\end{array}$ & $\begin{array}{l}\text { Eight plan } \\
(\mathbf{1 9 9 2 - 1 9 9 7 )}\end{array}$ \\
\hline Primary health centres & 11,000 & 21,854 \\
\hline Sub-centres & 83,000 & 132,730 \\
\hline Total beds & 514,989 & 596,203 \\
\hline Medical colleges & 106 & 146 \\
\hline $\begin{array}{l}\text { Annual admission in } \\
\text { medical colleges }\end{array}$ & 8,000 & 11,241 \\
\hline Dental colleges & 25 & 54 \\
\hline Allopathic doctors & 297,227 & 410,800 \\
\hline Nurses & 164,421 & 449,351 \\
\hline ANMs & 85,630 & 203,451 \\
\hline Health visitors & 13,612 & 22,144 \\
\hline Health workers (F) & 80,000 & 124,680 \\
\hline Health Workers $(\mathbf{M})$ & 80,000 & 63,871 \\
\hline Village health guides & 372,190 & 410,904 \\
\hline
\end{tabular}


Table 3: Financial investment in different plan periods (in crores). ${ }^{3}$

\begin{tabular}{|lllll|}
\hline Period & Total plan investment & Health & Family welfare & Water supply and sanitation \\
\hline Sixth plan (1980-85) & $97,500.00$ & 1821.05 & 1010.00 & 3922.02 \\
\hline Seventh plan (1985-90) & 180,000 & $3,392.89$ & $3,256.26$ & $6,522.47$ \\
\hline Annual plan (1990-91) & $61,518.10$ & 960.90 & 784.90 & 1876.80 \\
\hline Annual plan (1991-92) & $72,316.80$ & 1185.50 & 749.00 & 2514.40 \\
\hline Eight plan (1992-97) & $7,98,000.00$ & 7575.92 & 6500.00 & $16,711.03$ \\
\hline
\end{tabular}

\section{CONCLUSION}

Every goal of 'Health for All' has been interlinked with each other in some or the other way. Like, to reduce crude death rate, some eradication programmes were being improvised however at the same time those programmes helped to increase life expectancy of individuals by improving quality of life.

Plague or the Black Death has killed many people over the last several thousands of years, but understanding and preventing disease on a larger scale is something that really first came into focus during the beginning of the 1800 , when public health as a modern concept emerged. Several personalities come to mind during this period of our history and they are all relevant to the emerging of public health as a specific entity within medicine in our time.

To put it in a nutshell, public health has always been a key factor of all time since the beginning of the universe, we need to realize that to diminish health inequalities, we have to amalgamate ancient and advanced technology in an effective pattern to improve health and address health issues as they begin to develop.

\section{ACKNOWLEDGEMENTS}

We would like to thank Dr. Anup N. (Head and Professor, Department of Public Health Dentistry) for his expert advice and encouragement.

Funding: No funding sources Conflict of interest: None declared

Ethical approval: Not required

\section{REFERENCES}

1. Mahler H. The meaning of "health for all by the year 2000". InWorld Health Forum 1981;2:5-22.

2. Website. Reduce Child Mortality- the United Nations. Available at: https://www.un.org/ millenniumgoals/pdf/MDG_FS_4_EN.pdf. Accessed on 20 February 2020.

3. Park K. Preventive Medicine in Obstetrics, Paediatrics and Geriatrics. In: A textbook of Preventive and Social Medicine. 23rd Edition. Bhanot pubplishers; 2015:567.
4. Website. World Data Atlas: India- Infant Mortality Rate. Available at: https://knoema.com/atlas/ India/topics/Demographics/Mortality/Infantmortality-rate. Accessed on 20 February 2020.

5. Website. The World Bank: Mortality rate, infant. Available at: http://data.worldbank.org/ indicator/SP.DYN.IMRT.IN?end=2000\&start $=1960$. Accessed on 20 February 2020.

6. Park K. Health Programmes in India. In: Park's Textbook of Preventive and Social Medicine. 16th Edition. Bhanot pubplishers; 2000.

7. Hetzel BS, Pandav CS, eds. SOS for A Billion: The Conquest of Iodine Deficiency Disorders, Oxford University Press, New Delhi: 1994.

8. Website. World Health Organization: Blindness and Vision Impairment. Available at: www.who.int/mediacentre/factsheets/fs282/en/. Accessed on 20 February 2020.

9. Verma R, Khanna P, Prinja S, Rajput M, Arora V. The national programme for control of blindness in India. Australas Med J. 2011;4(1):1-3.

10. Park K. Health Planning and Management. In: A Textbook of Preventive and Social Medicine. 23rd Edition. Bhanot Publishers; 2015:876.

11. Website. National Malaria Control ProgrammeAarogya. Available at: http://www.aarogya.com/health-resources/healthprograms/national-malaria-control-programme.html. Accessed on 20 February 2020.

12. Kumar A, Valecha N, Jain T, Dash AP. Burden of Malaria in India: retrospective and prospective view. Am J Trop Med Hygiene. 2007;77(6):69-78.

13. Website. National Filaria Control ProgrammeAarogya. Available at: http://www.aarogya.com/healthresources/healthprog rams/nationalfilariacontrolprogramme.html?start=1. Accessed on 20 February 2020.

14. National Tuberculosis Institute, Bangalore. Yearbook on NTP in India. 1992-93. Available at: https://scialert.net/fulltext/?doi=ijp.2010.755.783. Accessed on 20 February 2020.

15. Aneja KS. Chemotherapy in national tuberculosis programme. NTI Newsletter. 1982;19(2and3):58-70.

16. Central TB Division, Directorate General of Health Services, Ministry of Health and Family Welfare, New Delhi. TB India; 2001:9-12.

17. Website. National Cancer Control ProgrammeAarogya. Available at: http://www.aarogya.com/healthresources/healthprog 
rams/nationalcancercontrolprogrammenccp.html.

Accessed on 20 February 2020.

18. Website. Guinea Worm Disease: Eradication Programme- CDC. Available at: https://www.cdc.gov/parasites/guineaworm/gwep.ht $\mathrm{ml}$. Accessed on 20 February 2020.

19. Website. United Nations General Assembly Special Session on HIV/AIDS 2006, India. Available at: https://data.unaids.org/pub/report/2006/2006_countr y_progress_report_india_en.pdf. Accessed on 20 February 2020.

20. Panda S, Chatterjee A, Abdul-Quader AS, eds, Living with the AIDS virus: The epidemic and the response in India. Pak Develop Rev. 2002:41(3);20.

21. Website. NACO Monograp NACP. Available at: http://www.naco.gov.in/sites/default/files/NACO $\% 2$ 0Monograp\%20NACP.pdf. Accessed on 20 February 2020.

22. Kakar DN, Kakar SN. Combating AIDS in the $21^{\text {st }}$ century Issues and Challenges. Sterling Publishers Private Limited; 2001: 32.

23. Website. National Japanese Encephalitis Control Programme- Aarogya. Available at: http://www.aarogya.com/healthresources/healthprog rams/nationaljapaneseencephalitiscontrolprogramme .html. Accessed on 20 February 2020.

24. Website. Health Services Database in the Context of National Health Accounts- Cehat. Available at: http://www.cehat.org/cehat/uploads/files/a197.pdf. Accessed on 20 February 2020.

25. National Health Policy Document, New Delhi, 2000. Govt. of India. Ministry of Health and Family Welfare. Available at: https://nptel.ac.in/content/storage2/courses/1091040 44/lecture_pdf/Lecture\%2034.pdf. Accessed on 20 February 2020. Accessed on 20 February 2020.

26. Website. National Health Policy document, New Delhi 2000. Ministry of Family and Health Welfare. Available at: https://main.mohfw.gov.in/ sites/default/files/4789632564521456.pdf. Accessed on 20 February 2020.

27. Merrick J. Public Health in a Global Context. Frontiers Public Health. 2013;1(9):1-3.

Cite this article as: Saxena A. Plan ahead by embracing retrospective approach: global health. Int J Community Med Public Health 2020;7:3754-61. 